\title{
ANALISA PLAT KONVENSIONAL DENGAN PLATE FLATES PADA GEDUNG BPN KOTAMADYA MALANG
}

\author{
${ }^{1 *}$ Musa Al Asyari, ${ }^{2}$ Yosep Cahyo SP., ${ }^{3}$ Sigit Winarto \\ Fakultas Teknik Universitas Kadiri \\ e-mail: ${ }^{1 *}$ musaalasyarii@gmail.com ${ }^{2}$ yosef.cs@unik-kediri.ac.id,${ }^{3}$ sigit.winarto@unik- \\ kediri.ac.id
}

\begin{abstract}
Reinforced concrete is a composite element consisting of concrete and reinforcing steel planted in concrete. The main properties of concrete are strong in compressive forces but weak in tensile forces. Reinforcing steel in concrete serves to cover these weaknesses, namely resisting tensile forces and some compressive forces. The strength of the concrete itself is based on mixed proportions, conditions of temperature and humidity where the concrete will harden. Plates flates is the right choice for the owner loss of aesthetics due to transverse beam. From the calculation results it turns out that no special shear reinforcement is needed, adjustments by enlarging the column dimensions, plate strength or thickness. $=694 \mathrm{KN}>V n=361,512 \mathrm{KN}$. To produce space efficiency that is expected, it is better to use plate flates. In terms of calculations it turns out that the plate flates need more reinforcement when compared to conventional plates.
\end{abstract}

Keywords : Conventional Plate, Plate Flate, Reinforced Concrete, Reinforcement

\begin{abstract}
Abstrak
Beton bertulang merupakan elemen komposit yang terdiri dari beton dan baja tulangan yang ditanam di dalam beton. Sifat utama beton adalah kuat didalam gaya tekan tetapi lemah di dalam gaya tarik. Baja tulangan dalam beton berfungsi untuk menutupi kelemahan tersebut yaitu menahan gaya tarik dan sebagaian gaya tekan. Kekuatan beton sendiri berdasarkan proposi campuran, kondisi temperature dan kelembaban dimana beton akan mengeras. Plate flates adalah pilihan yang tepat bagi owner menghendaki efisiensi ruang yang di harapkan tanpa harus kehilangan estetika karena balok melintang.Dari hasil perhitungan ternyata tidak diperlukan penulangan geser yang khusus,penyesuaian dengan memperbesar dimensi kolom,kekuatan atau tebal plat.karena setelah dicek penampang memenuhi persyaratan geser yaitu untuk kolom interior $\mathrm{Vc}=752 \mathrm{kN}>\mathrm{Vn}=653 \mathrm{kN}$ sedangkan kolom eksteriornya adalah : $\mathrm{Vc}=694$ $\mathrm{KN}>\mathrm{Vn}=361,512 \mathrm{KN}$. Untuk menghasilkan efisiensi ruang yang diharap maka,sebaiknya menggunakan plate flates. Dari segi perhitungan ternyata plate flates tersebut lebih banyak membutuhkan tulangan jika dibandingkan dengan plat konvensional.
\end{abstract}

Kata Kunci : Plat Konvensional, Plate Flate, Beton Bertulang, Penulangan 


\section{PENDAHULUAN}

Struktur bangunan gedung terdiri dari: komponen plat lantai, balok anak, balok induk[1][2]. Plat juga dipakai untuk atap dinding, \& tangga, jembatan atau pelabuhan. Petak plat dibatasi oleh balok anak pada kedua sisi panjang (L) dan oleh balok induk pada kedua sisi pendek (S)[3][4]. Komponen struktur beton dengan kerja sama itu disebut beton bertulang,dimana batang tulangan bertugas memperkuat dan menahan gaya tarik sedangkan beton hanya diperhitungkan untuk menahan gaya tekan. Sebagaimana diketahui bahwa beton hanya mampu menahan tegangan tarik yang kecil, tetapi dapat menahan tegangan tekan yang besar. Sedangkan baja akan dapat menyediakan tegangan tarik dan sebagian tegangan geser[5][6].

Lantai datar adalah suatu plat dua arah yang bercirikan tidak adanya balok-balok sepanjang garis kolom dalam, namun balok - balok pada tepi luar lantai boleh jadi ada atau tidak ada[7][8]. Dari segi analisis struktur perbedaan antara ada dan tidaknya blok-balok diantara garis kolom tidak bagitu penting, karena balok dengan suatu ukuran dapat direncanakan dapat berinteraksi dengan plat, maka penggunaan balok dengan ukuran nol hanyalah merupakan keadaan batas[9].

\section{METODE PENELITIAN}

\subsection{Tinjauan Umum}

Plat lantai merupakan struktur bangunan yang tidak berada diatas tanah secara langsung, artinya plat lantai merupakan lantai yang terletak di tingkat dua, tingkat tiga, dan seterusnya[10][11]. Dalam struktur ini dibingkai oleh balok beton yang kemudian di tapang kolom- kolom bangunan[12][13]. Faktor-faktor yang mempengaruhi antara lain besar lendutan yang di ijinkan, lebar bentang atau jarak antar balok pendukung dan bahan material yang digunakan[14].

Tabel 1. Perbedaan sifat fisik baja dan beton

\begin{tabular}{|l|c|c|}
\hline & Beton & Baja \\
\hline Kekuatan Tarik & JELEK & BAGUS \\
\hline Kekuatan Tekan & Bagus & $\begin{array}{c}\text { Bagus tetapi batang yang langsing } \\
\text { akan menekuk }\end{array}$ \\
\hline Kekuatan Geser & Cukup & Bagus \\
\hline Keawetan & Bagus & Berkarat bila tidak dilindungi \\
\hline Ketahanan & Bagus & Jelek, \\
\hline
\end{tabular}

Sumber: Pedoman SNI 


\subsection{Sifat-Sifat Beton}

A. Kekuatan Tekan Beton

Kekuatan tekan beton dinyatakan dengan (fc) yaitu kekuatan tekan beton dari hasil pengujian benda uji silinder yang dibuat dan di uji berdasarkan ketentuan pada pasal 1.3.SK SNI T-15-1991-03 [15].

\section{B. Kekuatan Tarik Beton}

Karena kekuatan tarik beton relative rendah, kira-kira 10\% sampai $15 \%$ dari kekuatan tekan, kadang-kadang 20\%. Kekuatan ini lebih sulit untuk di ukur dan hasilnya berbeda-beda[16][17][18][19].

\section{Aksi Komposit (Composit Action)}

Kekuatan tarik beton relatif kecil kira-kira hanya 10\% dari kekuatan tekan. Maka hampir semua kontruksi beton bertulang direncanakan dengan anggapan bahwa beton sama sekali tidak memikul gaya tarik[20][21]. Tulanganlah yang memikul gaya tarik tersebut. Apabila perletakan ini tidak mencukupi, batang baja tulangan akan menggelincir didalam beton dan disitu tidak akan terjadi aksi komposit[22]. Dengan demikian susunan tersebut harus diteliti sehingga beton dapat melekat dengan baik mengelilingi tulangan pada waktu pelaksanaan.Sebagai tambahan beberapa batang dibuat berusuk atau berayam sehingga diperoleh suatu perletakan mekanis tambahan.

\subsection{Pendekatan Struktur Plat Dua Arah}

Untuk membahas lenturan plat dua arah, pertama-tama ditinjau perilaku fisik suatu panel segi empat yang ditumpu oleh komponen struktur sangat kaku pada keempat sisinya, misalnya balok kaku atau dinding gaser. Apabila plat menahan beban luar termasuk beban grafitasi beban sendiri yang bekerja padanya, plat melendut membentuk cekungan seperti bentuk piring makan. Plat bersifat fleksibel dan umumnya bertulangan lemah maka redistribusi momennya akan sangat tergantung pada kekauan relatif komponen struktur terhadap plat yang ditumpunya.

\subsection{Momen Statis Total Terfaktor}

Untuk balok tumpuan sederhana momen statis total adalah $\mathrm{Mo}=1 / 8$, dibatasi oleh sumbusumbu panel yang bersebelahan pada tiap sisi dari sumbu tumpuan[23].

\subsection{Data Umum}

Lokasi rencana yang di jadikan pembahasan oleh penulis berada di gedung BPN Kotamadya Malang. Sekitar lokasi tersebut sebelah utara terdapat persawahan, Sebelah Selatan terdapat pasar madyopuro, Sebelah Timur terdapat toko sparepart mobil, Sebelah Barat terdapat Velodrom kota malang. 


\subsection{Pengumpulan Data}

Untuk meninjau kembali Analisa plat konvensional dengan plate flates pada Gedung BPN Kotamadya Malang, penulis memperoleh dari instansi terkait gambar dll. Adapun metode metode yang di gunakan yaitu metode observasi beserta instrumennya.

\subsection{Data Teknis Analisa Kedua Plat}

Dari data pengamatan yang dilakukan di gedung BPN Kotamadya Malang ini, kita bisa mengetahui rencana perbandingan plan konvensional dan plat flate yang akan digunakan Untuk gedung BPN Kotamadya Malang.

\section{HASIL DAN PEMBAHASAN}

\subsection{Dimensi Kedua Plat}

$6,00 \mathrm{~m}$

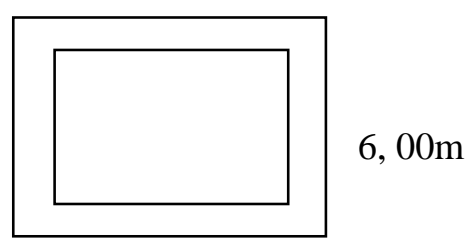

Jenis gedung

- Mutu beton (fc)

$=$ Kantor

- Mutu baja (fr

$=25 \mathrm{Mpa}$

Pembebanan Plat Flate

Beban Mati

- Berat sendiri: 0,185 x 2500

$=462,5 \mathrm{~kg} / \mathrm{m}^{2}$

- Berat sendiri adukan: 2 x 2

$=42 \mathrm{~kg} / \mathrm{m}^{2}$

Tegel: 2,5 x 24

$=60 \mathrm{~kg} / \mathrm{m}^{2}$

Qd

$=565,5 \mathrm{~kg} / \mathrm{m} 2 \approx 5,65 \mathrm{kNm}$

Beban Hidup q1

$=250 \mathrm{~kg} / \mathrm{m} 2 \approx 2,50 \mathrm{kNm}$
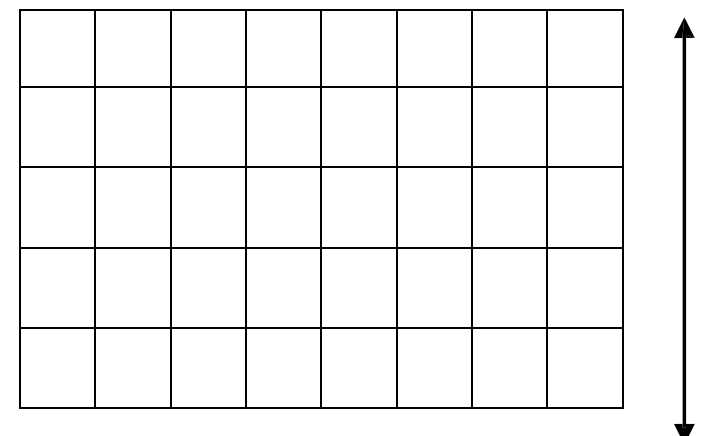

Pembebanan Plat Konvensional 


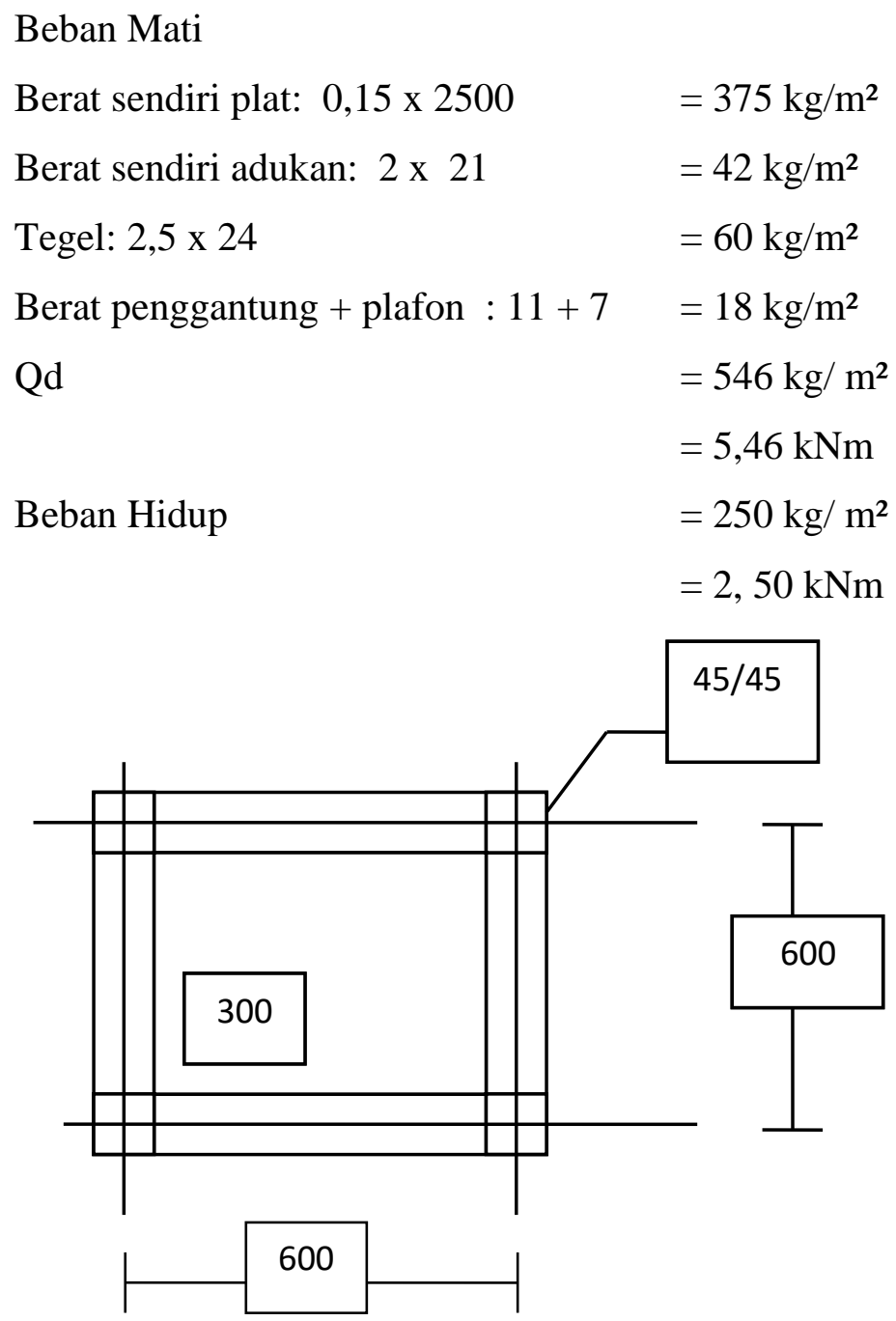

\subsection{Tulangan Plat Flate}

Momen tak imbang yang dilimpahkan ke kolom dengan lentur :

Karena c1 = c2 maka: $\mathrm{f}$

$\mathrm{Mnf}=\gamma \mathrm{fMn}=0,60(133,474)$

Momen dilimpahkan ke lajur selebar

$[\mathrm{c} 2+2(1,50 \mathrm{~h})] \mathrm{C} 2+2(1,5 \mathrm{~h})$

$=450+3(185)$

$$
=1005 \mathrm{~mm}
$$

Mnt $=$ Asfy $(\mathrm{d}-1 / 2 \mathrm{a})$ Perkiraan $(\mathrm{d}-1 / 2 \mathrm{a})$

$=0,90 \mathrm{~d}$, maka 80,084(10) $)^{-} 6=\operatorname{As}(400)(0,90)(160)$

As

$$
\begin{aligned}
& =1390 \mathrm{~mm} 2 \quad(\text { untuk lebar lajur } 1005 \mathrm{~mm}) \\
& =1390(400)-0,85(25)(1005) \\
& =26,035 \mathrm{~mm} \\
0,084(10)^{-} 6 & =\operatorname{As}(400)[160-1 / 2(26,035)]
\end{aligned}
$$


As

$$
=1362 \mathrm{~mm}
$$

Maka untuk tulangan tambahan digunakan tulangan D16 berjarak $100 \mathrm{~mm}$, dan di pasang lajur kolom selebar $500 \mathrm{~mm}$, kemudian dijangkarkan ke dalam kolom sesuai dengan panjang penyaluran yang diperlukan. Untuk pelimpahan momen geser pada daerah muka kolom di lakukan dengan cara yang sama, kadang-kadang dihadapi permasalahan pembebanan dan bentang yang tidak sama pada peninjauan suatu kolom interior.

Susunan tulangan sebagai berikut :

Daerah momen negatif kolom interior : $\quad 20 \mathrm{D} 14$ berjarak $150 \mathrm{~mm}$

Daerah momen positif kolom interior : $\quad$ 17D13 berjarak $170 \mathrm{~mm}$

Daerah momen negatif kolom eksterior: D13 berjarak $260 \mathrm{~mm}$

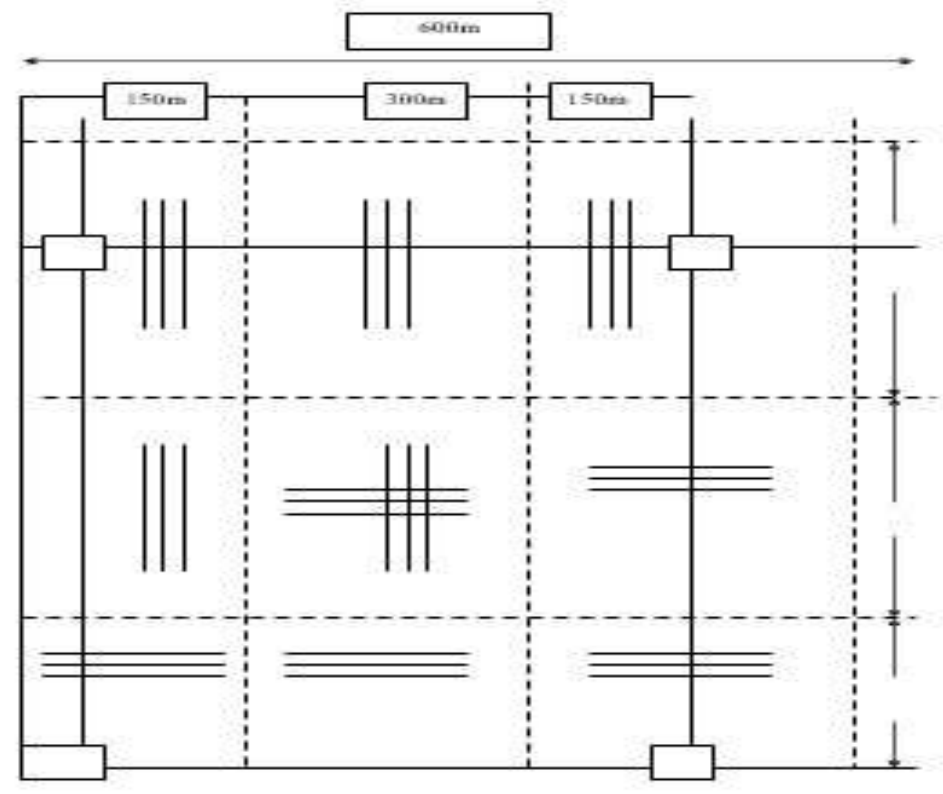

Gambar 1. Penulangan Plat Flate

\subsection{Tulangan Plat Konvensional}

Momen tumpuan terbesar yang diambil $\mathrm{Mn} \quad=17,493 \mathrm{kNm}$

$$
\mathrm{Mn}=\text { Asfy }(\mathrm{d}-1 / 2 \mathrm{a})
$$

Sebagai langkah awal dianggap (d-1/2a) $\quad=0,9 \mathrm{~d}$

$$
\begin{aligned}
& 17,493=\text { As }(400)(0,9)(120) \\
& \text { maka As } \quad=404 \mathrm{~mm} \\
& \mathrm{a}=\frac{\text { Asfy }}{0,85 \mathrm{fc}^{\prime} \mathrm{b}}=\frac{404(400)}{0,85(25)(1000)} \\
& =7,605 \mathrm{~mm}^{2} \\
& 17,493=\operatorname{As}(400)[120-1 / 2(7,605)] \\
& \text { didapat As } \quad=376 \mathrm{~mm} 2
\end{aligned}
$$

Di coba menggunakan batang tulangan

D12 $(113,1 \mathrm{~mm} 2)$ dengan jarak $S=\frac{113,1}{376}(1000)=300$ mm p.k.p 
Selanjutnya dengan cara yang sama dihitung luas tulangan yang diperlukan untuk masing - masing arah,baik untuk lajur kolom maupun lajur tengah.Karena batang tulangan saling menyilang dimana posisi tulangan arah melebar bangunan diatas tulangan memanjang bangunan.

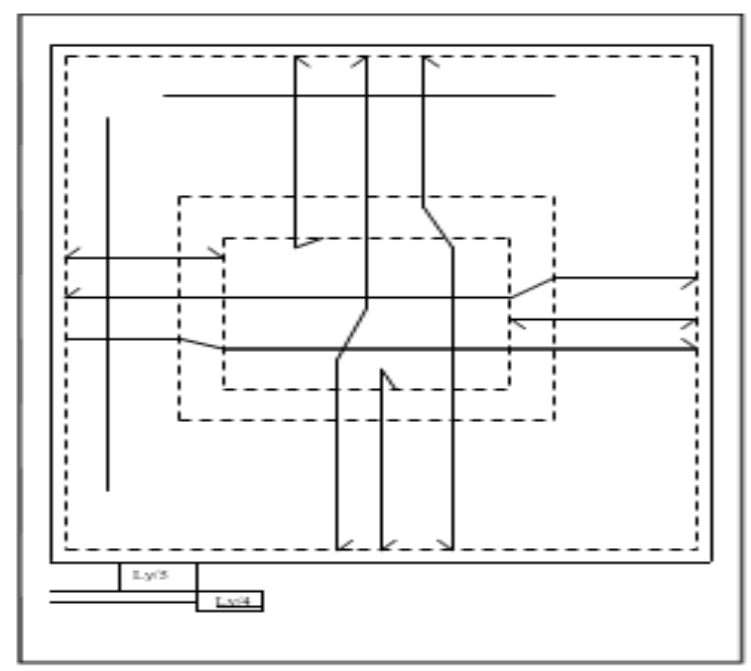

Gambar 2. Penulangan Plat Lantai 


\subsection{Perbandingan Mutu Plat}

Perbedaan antara plat konvensional dengan plate flates

Tabel 2. Perbedaan Fisik Antara Plat Konvensional Dengan Plate Flates

\begin{tabular}{|c|c|}
\hline Plat Konvensional & Plate Flates \\
\hline Plate slab lebih tipis & Plate slab lebih tebal \\
\hline Tulangan lebih renggang & Tulangan lebih rapat \\
\hline Terdapat balok & Tidak ada balok \\
\hline $\begin{array}{c}\text { Tidak ada penebalan plate di area } \\
\text { kolom }\end{array}$ & Ada penebalan plate di area kolom \\
\hline Lebih mahal & $\begin{array}{c}\text { Lebih murah karena volume beton } \\
\text { berkurang }\end{array}$ \\
\hline Pekerjaan lebih lama & Pekerjaan lebih cepat \\
\hline
\end{tabular}

Tabel 2. Perbedaan Kekuatan Antara Plat Konvensional Dengan Plate Flates

\begin{tabular}{|l|l|}
\hline Plat Konvensional & \multicolumn{1}{c|}{ Flates Plates } \\
\hline In $1=5,70 \mathrm{~m}$ & In $1=5,55 \mathrm{~m}$ \\
In $2=5,70 \mathrm{~m}$ & $\mathrm{In} 2=5,55 \mathrm{~m}$ \\
$\beta \mathrm{s}=1$ & $\beta \mathrm{s}=0,75$ \\
$\alpha \mathrm{m}=1,86$ & $\alpha \mathrm{m}=0(\mathrm{karena}$ tanpa balok tepi) \\
$\mathrm{h}=150 \mathrm{~mm}$ & $\mathrm{~h}=164,4 \mathrm{~mm}+10 \%=180,84 \mathrm{~mm}$ \\
$\mathrm{be}=1000 \mathrm{~mm}$ & $\mathrm{Wu}=11 \mathrm{KPa}$ \\
$\mathrm{Y}=174,057 \mathrm{~mm}$ & Kolom Interior \\
Lb $=1.253 .322 .463 \mathrm{~mm} 4$ & $\mathrm{Vu}=391,907 \mathrm{KN}$ \\
Ls1=1.687.499.999 mm4 & $\mathrm{Ac}=390,400 \mathrm{~mm}^{2}$ \\
$\alpha 1=0,743$ & $\mathrm{Vn}=653 \mathrm{KN}$ \\
Is $2=168.749 .999 \mathrm{~mm} 4$ & $\mathrm{Vc}=752 \mathrm{KN}>\mathrm{Vn}=653 \mathrm{KN}$ \\
& Kolom Eksterior \\
& $\mathrm{Vu}=216,907 \mathrm{KN}$ \\
& $\mathrm{Vn}=361,512 \mathrm{KN}$ \\
& $\mathrm{Ac}=267200 \mathrm{~mm}^{2}$ \\
& $\mathrm{Vc}=694 \mathrm{KN}>\mathrm{Vn}=361,512 \mathrm{KN}$ \\
\hline
\end{tabular}




\section{KESIMPULAN DAN SARAN}

\subsection{Kesimpulan}

Berdasarkan hasil analisa permasalahan yang telah diuraikan diatas, dapat disimpulkan:

1. Dari segi design penulangan plat konvensional lebih renggang dan tipis karena banyak balok yang menumpunya semakin panjang bentang plat semakin besar balok yang menumpunya.

2. Dari hasil perhitungan ternyata tidak diperlukan penulangan geser yang khusus, penyesuaian dengan memperbesar dimensi kolom, kekuatan atau tebal plat. Karena setelah dicek penampang memenuhi persyaratan geser yaitu untuk kolom interior $\mathrm{Vc}$ $=752 \mathrm{kN}>\mathrm{Vn}=653 \mathrm{kN}$ sedangkan kolom eksteriornya adalah: $\mathrm{Vc}=694 \mathrm{KN}>\mathrm{Vn}$ $=361,512 \mathrm{KN}$

3. Dari segi design plate flate lebih rapat dan tebal karena tidak ada balok yang menumpunya.

4. Untuk perbedaan design keduanya, plat flate menggunakan kolom interior dan eksterior sedangkan untuk plat konvensional seluruhnya beban di tampang oleh balok-balok. Karena tidak adanya balok-balok itu tebal plat flates ditambah $10 \%$.

5. Untuk menghasilkan efisiensi ruang yang diharap maka, sebaiknya menggunakan flate plates. Dari segi perhitungan ternyata flate plates tersebut lebih banyak membutuhkan tulangan jika dibandingkan dengan plat konvensional.

\subsection{Saran}

1. Untuk bangunan gedung dengan beban hidup kecil dan menghandaki efisiensi ruang, maka sebaiknya menggunakan flate plates. Sebaiknya apabila gedung direncanakan menerima beban hidup besar, maka sebaiknya menggunakan plat konvensional.

2. Flate plates adalah pilihan yang tepat bagi owner menghendaki efisiensi ruang yang diharapkan tanpa harus kehilangan estetika karena adanya balok-balok melintang.

\section{DAFTAR PUSTAKA}

[1] D. R. Teruna and S. Prawira, "Studi Perbandingan Penggunaan Flat Plate Dan Flat Slab Dengan Drop Panel Pada Struktur Bangunan Ditinjau Dari Segi Volume," Univ. Sumatera Utara. Medan, 2017.

[2] M. I. Syamsi, "Perbandingan Analisis Two Way Slab With Beam dengan Flat Slab (Studi Kasus: Coal Yard PLTU Kalimantan Barat),” Semesta Tek., vol. 18, no. 2, pp. 168-175, 2016.

[3] M. C. Munawar, "KAJIAN STRUKTUR BANGUNAN GEDUNG POLITEKNIK PERKAPALAN ITS DENGAN SISTEM PLAT DAN BALOK BIASA 
KONVENSIONAL DIBANDINGKAN SISTEM STRUKTUR FLAT SLAB DENGAN DROP PANEL DITINJAU DARI ESTETIKA, BIAYA DAN WAKTU," EXTRAPOLASI J. Tek. Sipil, vol. 7, no. 01, 2014.

[4] A. Setiyono, "STUDI PERBANDINGAN PERENCANAAN STRUKTUR MENGGUNAKAN METODE RIGID FRAME DENGAN METODE FLAT PLATE DI TINJAU DARI VOLUME BETON BERTULANGNYA,” SKRIPSI Jur. Tek. SipilFakultas Tek. UM, 2012.

[5] Z. Muttaqin and I. M. T. Irijanto, "Pengujian Efektivitas Penukar Kalor Multi Flat Plate Heat Exchanger Aluminium dengan Aliran Cross Flow.” Mechanical Engineering Departement, Faculty Engineering of Diponegoro University, 2012.

[6] R. A. N. PERMATA, "PERENCANAAN ULANG KONSTRUKSI BANGUNAN ATAS HERO HQ IN BINTARO DENGAN SISTEM FLAT PLATE.” University of Muhammadiyah Malang, 2015.

[7] N. A. Prasetya, "Studi Lebar Efektif Struktur Flat Plate Dengan Hollow-Dua Arah Dibawah Beban Gempa.” Institut Technology Sepuluh Nopember, 2016.

[8] L. Hemawan, "A STUDY ON THE EFFECTIVE WIDTH OF SLAB IN FLAT PLATE STRUCTURES UNDER SEISMIC LOADING,” 2010.

[9] A. Ibrahim, M. Y. Othman, M. H. Ruslan, S. Mat, and K. Sopian, "Recent advances in flat plate photovoltaic/thermal (PV/T) solar collectors," Renew. Sustain. energy Rev., vol. 15, no. 1, pp. 352-365, 2011.

[10] T. Yousefi, F. Veysi, E. Shojaeizadeh, and S. Zinadini, “An experimental investigation on the effect of A12O3-H2O nanofluid on the efficiency of flat-plate solar collectors," Renew. Energy, vol. 39, no. 1, pp. 293-298, 2012.

[11] F. Jafarkazemi and E. Ahmadifard, "Energetic and exergetic evaluation of flat plate solar collectors," Renew. energy, vol. 56, pp. 55-63, 2013.

[12] J. J. Michael, S. Iniyan, and R. Goic, "Flat plate solar photovoltaic-thermal (PV/T) systems: A reference guide," Renew. Sustain. energy Rev., vol. 51, pp. 62-88, 2015.

[13] M. A. A. Hamad, I. Pop, and A. I. M. Ismail, "Magnetic field effects on free convection flow of a nanofluid past a vertical semi-infinite flat plate," Nonlinear Anal. Real World Appl., vol. 12, no. 3, pp. 1338-1346, 2011.

[14] S.-M. Kang, T.-S. Eom, and J.-Y. Kim, "Reshoring effects on deflections of multishored flat plate systems under construction," Struct. Eng. Mech., vol. 45, no. 4, pp. 455-470, 2013.

[15] Maryanto, S. Winarto, and L. D. K, "STUDI EKSPERIMENTAL PENGARUH PENAMBAHAN LIMBAH KUNINGAN TERHADAP KUAT TEKAN BETON 
MUTU K-225,” Jurmateks, vol. 1, no. 1, pp. 76-90, 2018.

[16] D. A. Fanella, M. Mahamid, and M. Mota, "Flat plate-voided concrete slab systems: design, serviceability, fire resistance, and construction," Pract. Period. Struct. Des. Constr., vol. 22, no. 3, p. 4017004, 2017.

[17] Z. Chen, M. Gu, and D. Peng, "Heat transfer performance analysis of a solar flat-plate collector with an integrated metal foam porous structure filled with paraffin," Appl. Therm. Eng., vol. 30, no. 14-15, pp. 1967-1973, 2010.

[18] A. I. Candra, “Analisis Daya Dukung Pondasi Strauss Pile pada Pembangunan Gedung Mini Hospital Universitas Kadiri," Ukarst, vol. 1, no. 1, pp. 63-70, 2017.

[19] A. I. Candra, E. Gardjito, Y. Cahyo, and G. A. Prasetyo, "Pemanfaatan Limbah Puntung Rokok Filter Sebagai Bahan Campuran Beton Ringan Berpori,” pp. 1-8.

[20] H.-T. Yu and L. Bernal, "Effect of pivot point on aerodynamic force and vortical structure of pitching flat plate wings," in 51st AIAA aerospace sciences meeting including the new horizons forum and aerospace exposition, 2013, p. 792.

[21] C. M. Ikeda, Fluid Structure Interactions: Implosions of Shell Structures and Wave Impact on a Flat Plate. University of Maryland, College Park, 2012.

[22] F. Lefèvre, S. Lips, R. Rullière, J.-B. Conrardy, M. Raynaud, and J. Bonjour, "Flat plate heat pipes: from observations to the modeling of the capillary structure," Front. Heat Pipes, vol. 3, no. 1, 2012.

[23] W. T. Koiter, "General theory of mode interaction in stiffened plate and shell structures," 1976. 